\title{
ON PREPOSING AND WORD ORDER RIGIDITY ${ }^{1}$
}

\author{
Asha Tickoo
}

\section{Introduction}

The expression 'word order freedom' is commonly used to evoke a distinguishing feature of verb-final ( $v$-f for future reference) languages, their tolerance of scrambling. In at least one $\mathrm{v}$-f language Kashmiri, however, 'freedom' is also apparent in a mode of word order flexibilty quite distinct from the accommodation of scrambling. I will demonstrate that felicitous preposing ${ }^{2}$ in $\mathrm{v}$-f Kashmiri1 is possible under weaker functional conditions than those constraining its counterpart in the verb-medial language ( $\mathrm{v}-\mathrm{m}$ for future reference) English $^{3}$. This less severely constrained preposing evidences hitherto unrecorded word order freedom, and also makes it reasonable to pose a question about the level of functional similarity of all comparable constructions in $v$-f and $v-m$ languages, a question that addresses the possibility of a systemic difference in their word order rigidity. If there are weaker functional constraints on comparable constructions in $v-f$ than in $v-m$, v-f must capture broader, i.e, less subtle pragamtic distinctions by means of word order. Perceived in the backdrop of the assumption of fundamental syntactic iconicity - cross-linguistic similarity of form is

${ }^{1}$ Earlier versions of this paper were presented at SALA XIII, 1991, and the 20th annual Univ. of Wisconsin-Milwaukee Linguistic Symposium, on Word Order in Discourse, 1991. Some of the ideas are taken from chapters 3, 4 and 5 of Tickoo (1990). I am grateful to Anthony Kroch, Gillian Sankoff, Ellen Prince, Talmy Givon and Masayoshi Shibatani for their helpful suggestions. All shortcomings are, however, my own.

2 In order to properly understand which constructions qualify as preposings, it is necessary to mention that Kashmiri is a v-f language with a verb-second rule; there are no v-f matrix clauses. It is also relevant to mention that Kashmiri allows both subject and object deletion under the right discourse conditions. And since $\mathrm{v}$-f order is not found in matrix clauses, it is reasonable to assume that subject deletion follows preposing. And, therefore, clauses 1 and 2, below, both quality as preposings:

1. tim dit asi vejsan them gave we girl friends-to

$=\quad$ We gave them to our girl friends.

2. tim dit vejsan them gave girl íriends-to

$=\quad$ We gave them to our girl friends.

${ }^{3}$ l am limiting my study to an analysis of the preposing of verb complements other than temporal adverbs. 
consonant with similarity of coded functional domain (Givon 1984), such a difference would be apparent in fined-grained comparison of largely common cross-linguistic modes of denoting pragmatic meaning. This paper will give evidence of a previously unobserved dimension of word order freedom in a little-studied v-f language, and by doing so hope to motivate research interest in the possiblity of $v$-f and $v-m$ as subtly differentiated systems by which pragamtic meaning is coded.

I will first suggest that there are functional constraints that are common to preposing in $v-f$ and $v-m$ languages and which separate it from fronting by scrambling. The difference between preposing and fronting by scrambling is demonstrated using examples from Hindi, because Kashmiri does not allow fronting by scrambling, and Hindi is like Kashmiri both Indo-Aryan and v-f, but permits both preposing and fronting by scrambling ${ }^{4}$. I will then

1) review the existing findings on, and where necesssary add to, those defining conditions on English preposing which are useful in its insightful comparison with Kashmiri preposing, and

2) subsequently identify the dissimilarities in the constraints on felicitous Kashmiri preposing.

This comparative analysis will provide evidence of my principal finding, that whereas preposing is set apart from fronting by scrambling by being constrained to mark an atemporal relationship to its preceding clause, felicitous preposing in $\mathrm{v}-\mathrm{f}$ Kashmiri is less given than in it is in $\mathrm{v}$-m English.

In my assessment of levels of givenness, I will use Prince's (1981a) three levels of givenness:

1) predictable/recoverable given: "The speaker assumes that the hearer can predict or could have predicted that a particular item will or would have occurred in a particular position within a sentence" (Prince 1981a: 226)

2) salient given: "The speaker assumes that the hearer has or could appropriately have some particular thing/entity ... in his/her consciousness at the time of hearing the utterance" (Prince 1981a: 228) (I have sometimes used the term 'presupposed' with meaning equivalent to salient given), and

3) shared knowledge given: "The speaker assumes, or can infer a particular thing (but is not necessarily thinking about it)." (Prince 1981a: 230)

The preposings analysed in this study are a combination of naturally occurring constructions and those formulated to illustrate a specific point in the discussion. The naturally occurring Kashmiri preposings are taken from recorded narratives. A number of the English preposings are taken from Ward (1985), and these constructions are all naturally occurring.

\footnotetext{
${ }^{4}$ For the remainder of the paper we study Kashmiri preposing, although my intuitions about Hindi suggest that our claims are equally applicable to Hindi preposing.
} 


\section{Conditions unique to preposing and those unique to English preposing}

In Hindi, a direct object can be fronted by scrambling in the environment of a preceding temporal adverb, as is demonstrated in $1 \mathrm{~b}$ :

1 a. shila ne bohothsa khana pakaya

Sheila by a-lot-of food cooked

$=$ Sheila cooked a lot of food.

b. aur fir wo khana usne gariib loogu(n) me(n)

and then that food she poor people amongst

baanta

distributed

$=$ Then she distributed that food amongst the poor.

The felicitous preposing of verb complements other than temporal adverbs both in Hindi, and in Kashmiri and English, however, requires that the clause bear an atemporal relationship to the preceding clause, demonstrated by $2 \mathrm{~b}$ and $3 \mathrm{~b}$ :

2
a. kuc bhi nahi khata?
nothing not eats
$=$ Doesn't he eat anything?
b. eek buund pani bhi wo nahi pita (\#fir)
one drop of water even he not drinks (\#then)
$=$ He doesn't even drink a drop of water.
(example taken from Hindi)

3 a. The had a baby boy.

b. Tom they called him (\# after that).

While both $2 b$ and $3 b$ are atemporally sequenced clauses, the open proposition of $2 b$ (obtained by substituting a variable for the focal constituent; OP for future reference) is shared knowledge given, while the OP of $3 b$ is salient given. As a consequence, $2 b$ is not a felicitous English preposing, demonstrated in 4b, because English preposing differs from its Kashmiri and Hindi counterparts in constraining the OP to be salient given, rather than merely shared knowledge given ${ }^{5}$.

4 a. He kept a strict fast.

b. \# 'A drop of water he didn't even have.

He didn't even have 'a drop of water.

$5 \mathrm{~b}$ which marks an atemporal relationship and has propositional content that is salient given is a felicitous English preposing:

${ }^{5}$ The exception to this constraint in English preposing is the dialectally restricted YiddishMovement, found in dialects of English that have been influenced by Yiddish substratum. YiddishMovement is like Kashmiri and Hindi preposing in being constrained to be only shared knowledge, rather than salient given. (cf. Prince 1981b; Ward 1985). 
5 a. Have you read my dissertation yet?

b. 'Half of it I've read.

\subsection{Features consonant with salience}

Consonant with the condition of salience on English preposing are two other defining features: 1) Prince (1981b, 1984) and Ward (1985) point out that the construction comprises two distinct functional constituents. 2) I will demonstrate that in felicitous preposing there is correlation between the independent functions at these poles.

\subsubsection{Bipolar distribution}

While most descriptions of English preposing have identified it as a topic creating device (cf. Halliday 1976; Gundel 1974; Langacker 1974; Rodman 1974; Creider 1979; Bland 1980; Reinhart 1981 \& Davison 1984), Prince and Ward claim that preposing is in fact functionally bipolar, comprising two separate constituents, 1) the preposed constituent and 2) the OP, each of which are independently salient given. This is illustrated in $6 \mathrm{~b}$ and $7 \mathrm{~b}$ :

Focus Movement:

6 a. The contras devised a new strategy.

b. Guerilla Warfare, they called it.

(From Ward 1985)

In $6 \mathrm{~b}$, the salient $\mathrm{OP}$, obtained by substituting a variable for the focal constituent, is 'They called it $\mathrm{x}$ ( $\mathrm{x}$ : an element of the set of names of strategies)', and the salient preposed constituent 'Guerilla Warfare' is an instantiation of the variable $\mathbf{x}$.

Topicalization:

7 a. I made two minor mistakes.

b. One apparently 'everyone in the class made.

Likewise, in $7 \mathrm{~b}$, the salient $\mathrm{OP}$ is ' $\mathrm{x}$ made (some-number-of-mistakes), where $\mathrm{x}$ is on the scale (members-of-the-class)'; and the salient preposed constituent 'one' is an instantiation of the nonfocal variable 'some-number-of-mistakes'.

\subsubsection{Scalar relationships}

Before illustrating the consonance constraints between the salience of preposed constituent and OP, it is necessary to briefly explain the notion of salience.

The relationship of salience of both preposed constituent and focus, in Topicalization, in which the focus is not the preposed constituent, is described by Ward (1985) as 'scalar'. Scalarity constitutes the perception of phenomena in terms of such relationships as part to whole, subset to set, greater than, less than, attribute to entity, 
or as the relationship of equality.

At the time of the utterance of $6 \mathrm{~b}$, above, the speaker assumes that the interlocutor is attending both to the strategy and the conception of it as possessing certain types of attributes. The name 'Guerilla Warfare' is an instance of this presupposed relationship of attribution.

Likewise at the time of the utterance of $8 \mathrm{~b}$, the speaker assumes that the interlocutor is attending to the entity 'all nuts' of $8 \mathrm{a}$ and the perception of it as a set comprising elements. The preposed constituent of $8 \mathrm{~b}$ is an instance of this element of set perception of 'all nuts'.

8 a. I like all nuts.

b. Peanuts I love.

9 through 15 are some more examples of the scalar salient relationships of the preposed constituent (cf. Ward 1985 for a more detailed discussion of these):

$9 . \quad$ Lower value:

Do you like this album?

Yea, this song I really like. (Ward 1985: 69)

10. Higher value:

Have you filled out the Summary Sheet?

Yea. Both the 'Summary Sheet and the Recording Sheet, I've done. (Ward 1985: 69)

11. Alternative value:

Did you get any more clues to the crossword puzzle?

No. The cryptogram I can do like that. The crossword puzzle is 'hard. (Ward 1985: 70)

12. Entity/ Attribute:

We had to buy this reading packet.

'Twenty dollars it cost. (Ward 1985: 71)

13. Set/Subset

Do you watch much sports?

Football I watch.

14. Part/Whole:

How do you like your new job? I like a lot of it. Parts of it I 'don't like at all. (Ward 1985: 71)

15. Identity:

(This is a relationship found only in the exceptional case of what Ward (1985) calls propositional affirmation)

They wanted him to go to school.

To school he went.

I want to suggest that it is also possible to characterize the salience of the OP in terms 
of scalar relationships. In illustration, I will identify three types of salient OP relationships: attribution, as in 16, prerequisite to, as in 17, and alternative to, as in 18:

16 a. At bottom, things just are the way they are, a heterogeneous reality. Yet parts of this reality have the capacity for perception, for acquiring information from other parts, and an accompanying capacity for acting on still others.

(b) Those parts having the capacity for perception and action we call 'organisms. (Ward 1985: 279)

OP: We call (a part of reality) y (y:names of such parts)

17 a. G: So, how did it (prelims) go?

S: $\quad$ The historical question, I had some problems with, but I think it's ok.

(b) The descriptive, I 'just wrote a whole lot. We'll see. (Ward 1985: 280)

OP: I did (a section of the exam) in y manner (y: a way of performing the exam)

18. N: Don't you feel anything?

M: $\quad$ What I feel I' control. (Ward 1985: 290)

OP: I y (y: feel or control) (some part of what is

potentailly feelable)

In 16 , the OP, obtained by substituting a variable for the focal constituent of $16 \mathrm{~b}$, - 'we call (a part of reality) y (y: names of such parts)' - relates attributively to 16a and is therefore salient to the existence of certain types of reality. The relationship of naming is not salient as a result of being previously mentioned, but because the act of naming is presupposed by the existence of certain types of entities, phenomena or acts.

In 17 , the OP, obtained by substituting a variable for the focal constituent of $17 \mathrm{~b}$, - 'I did (a section of the exam) in y manner ( $y$ : a way of performing the exam)' is prerequisite to taking the exam, i.e., performing the exam (or some part thereof in some way) is implicit in the taking of the exam. And therefore it is infelicitous to state the presupposition of $19 \mathrm{~b}$ in the context of 19a:

19 a. How did it (prelims) go?

I had some problems with the historical question, but I think it's ok.

b. I performed some part of the exam in a certain way.

In 18 , the OP, obtained by substituting a variable for the focal constituent of $18 \mathrm{M}$, - 'I $y$ ( $y$ : feel or control) (some part of what can be felt)' - implies that the possibility for the alternative states of feeling or controling, is presupposed by $18 \mathrm{~N}$. This is demonstrated by the fact that it is infelicitous to state this presupposition in the context of $18 \mathrm{~N}$, as is shown in 20 :

20.

Don't you feel anything?

Either I feel something or I don't feel anything.

The three above-defined scalar salient relationships of the OP, attribution, alternation 
and prerequisite to, do not necessarily cover the full range of OP relationships; and more extensive study is needed to achieve this.

\subsubsection{Correlation between the functions at the poles}

Bipolar preposing, each pole of which is individually scalar salient, shows consonance between the salience of preposed constituent and accompanying proposition. This is exemplified in 21 through 28 below:

21 a. I like all candy.

b. Other food, I just eat.

22 a. I like food.

b. \# Candy, I just eat.

23 a. I like all candy.

b. \# Food, I adore.

24 a. I like all food.

b. Candy, I adore.

In $21 \mathrm{~b}$, the OP bears the less than relationship to the proposition of the preceding clause, and its accompanying preposed constituent relates as the less palatable and merely essential whole set to the more palatable and desirable element of this set of the preceding clause. There is consonance between the relationship of whole set of less palatable but essential, of the preposed constituent, and the less than relationship, of its accompanying OP, and therefore the preposing of $21 \mathrm{~b}$ is felicitous in the context of 21a. Put differently, when an element of the whole is liked, the whole being just tolerated is salient. The reverse is not true. That is, given that I like the whole set, it cannot be salient that I merely tolerate an element of it, and this is illustrated in 22 . Therefore, $21 \mathrm{~b}$ and $22 \mathrm{~b}$ illustrate that the whole set to the element can accommodate the less than relationship, while the element of the set to the whole cannot accommodate this relationship. This makes predictions about the felicity of other preposing, for example, $25 \mathrm{~b}$ and $26 \mathrm{~b}$ :

25 a. I like football.

b. Other types of competitive sports I just tolerate.

26 a. I like all sports.

b. \# Football I just tolerate.

The preposings of $23 \mathrm{~b}$ and $24 \mathrm{~b}$ illustrate that the relationship of greater than is accommodated by element in set to whole set, but is not accommodated by whole set to element in set. If I like all food then my adoring some particular type of food is salient; if, on the other hand, I like some particular type of food, it is not salient that I adore all types of food. This relationship of consonance between element in the set of and greater than, and want of consonance between whole to element and greater 
than again makes predictions about the felicity of other preposings, for example, $27 \mathrm{~b}$ and $28 \mathrm{~b}$ :

27 a. He has mastered every kind of competitive sport.

b. Football he is very skilled at.

28 a. He has completely mastered the game of football.

b. \# All kinds of sports he is very skilled at.

\subsection{The exceptional cases}

The above-described general features on felicitous English preposing, that it is functionally bipolar with preposed constituent and OP marking independent but consonant scalar salient relationships, do not in themselves account for the exceptional behaviour of the three following types of preposing:

1. the preposing of main verbs (cf. Ward 1985, 1990),

2. preposing constituents which relate back with the scalar relationship of identity, and 3. preposing adjectives, adverbs of manner and pronouns.

\subsubsection{VP preposing}

Ward (1985) points out that English main verbs are not felicitously preposed merely by meeting the general condition of salient preposed constituent and salient OP, as is demonstrated by $29 \mathrm{c}$ :

29 a. They've had a baby.

b. 'Tom they've called him.

c. \# Called him Tom they have.

Rather, they are only felicitous when they meet this general condition by affirming or denying a presupposition:

30 a. They wanted him to talk.

OP: He x (x:did/did not) talk.

b. And talk he 'did./ But talk he would hot.

Unlike $29 \mathrm{c}$, the main verb preposing of $30 \mathrm{~b}$ meets the general constraint of salient preposed constituent and OP by affirming the presupposition, that he either did or did not talk, and it is therefore a felicitous VP preposing.

\subsubsection{The non-identity condition}

A feature of English preposing, not discussed in the existing literature, is the preposed constituent's intolerance of the identity relationship. Whereas the preposed constituent 
can be in any other way scalar salient, it cannot bear the relationship of identity. Therefore, while $31 \mathrm{~b}$ is felicitous, because the preposed constituent relates to its preceding discourse with the relationship of part to whole, instantiating the OP: You $\mathrm{x}$ (x:read or did not read) (a part of my dissertation), 32b where the preposed constituent bears the identity relationship is not felicitous. It is only felicitous if the listener interprets 'dissertation' as an element of a salient set. In other words, the OP 'You x (x:read or did not read) my dissertation' cannot be instantiated. That is, the OP is constrained to contain a variable for the constituent instantiated by the preposed constituent.

31 a. Did you read my dissertation?

b. Half of it I read.

32 a. Did you read my dissertation?

b. \# Your dissertation I read.

c. I read it.

\subsubsection{Preposing adjectives, adverbs of manner and pronouns}

Ward (1985) shows that preposed English adjectives, adverbs of manner and pronouns are almost always infelicitous, but offers no explanation for this. I will argue that these preposings are made infelicitous by the identifying constraint of salience on English preposing, because the OPs of preposed adjectives, adverbs of manner and pronouns are not in general salient given.

33. A: Mary is intelligent and beautiful.

B: \# Beautiful she is 'not./ She isn't beautiful.

The adjectival preposing of $33 \mathrm{~B}$ is infelicitous because it presupposes that Mary is either beautiful or intelligent, which is evident in the fact that $\mathrm{B}$ is an instance of the OP Mary $\mathrm{x}$ ( $\mathrm{x}$ : is/is not) (an element in the set of beautiful and intelligent), obtained by substituting a variable for the focal constituent of B. But that Mary is either intelligent or beautiful is not presupposed at the time of the utterance of $33 \mathrm{~B}$, in the context of $33 \mathrm{~A}$. It is only presupposed in the context of $34 \mathrm{~b}$ after $34 \mathrm{a}$, and in this context, therefore, it becomes possible to felicitously prepose the adjective:
a. A: Mary is intelligent and beautiful.
b. B: She is beautiful,
c. but intelligent she is not.

The adverbial preposing of $35 \mathrm{~B}$ is also infelicitous because its OP is not salient in the context of $35 \mathrm{~A}$ :

35. A: Mary read slowly and carefully.

B: \# Carefully she did not read.

The preposing of B presupposes that Mary read either carefully or slowly, but this 
cannot be presupposed in the context of A. Oddly enough, this preposing does not become felicitous in the context of 36b after 36a, although the above mentioned presupposition does hold in this context. One of the shortcomings of this analysis is its failure to explain this infelicity:

36 a. Mary read slowly and carefully.

b. She did read slowly,

c. \# but carefully she did not read.

For pronominal preposing, again the OP is not salient, except in one clearly specifiable discourse context, to be described below.

37 a. I like Paul.

b. \# In fact, him I love./ In fact, I love him.

In 37 , the pronominal preposing is ruled out by the nonidentity condition, by which the OP must contain a variable for the constituent instantiated by the preposed constituent (cf. section 2.2.2). The preposing of $37 \mathrm{~b}$ presupposes that I feel some degree of liking differing from mere liking, i.e., more or less than mere liking, for Paul. But this is not salient in the context of its preceding discourse. That is, my liking Paul does not allow for the presupposition that I feel either more or less than just that for him, and hence the infelicity of this preposing.

38 a. I like all my brothers.

b. Paul I love.

If we reconstruct the example of 37 as in 38 , so that the preposed constituent marks an element in set relationship, rather than identity, the OP obtained by substituting a variable for the focal constituent of this preposing, namely, I x (x:feel some degree of liking) for (a member of the set of my brothers) is salient. This implies that 'liking' is only presupposed as measurable on a gradient when it applies to a set of likable people. When it applies to only one individual, as in 37 , its perception as gradable is not presupposed.

39 a. I met John and Mary last night.

b. John I met first.

c. \# Him I met first./ I met him 'first.

In $39 \mathrm{~b}$, the nominal preposing is felicitous because it is does not relate back with identity, but rather with the relationship of element in set. The pronominal preposing of $39 \mathrm{c}$, on the other hand, is infelicitous because it is unable to select an element from a salient set. Pronominal preposing becomes felicitous, however, in the following context:

40 a. I met John and Mary last night.

b. I met her first,

c. and him I met later.

Presupposed in the context of the propositional sum of $40 \mathrm{a}$ and $\mathrm{b}$ is $\mathrm{d}$, below: 
d. I met the other some time after.

And it is this presupposed 'other' that the preposed pronoun of $40 \mathrm{c}$ refers to. Here the pronoun can be preposed because it is not required to select an element from a salient set as it is in $39 \mathrm{c}$, nor to refer back with identity as in $37 \mathrm{~b}$, but to refer back to an already selected element of a salient set. This is evidence of the highly constrained conditions under which pronominal preposing is felicitous. While, preposed pronouns are constrained by the general rule which disallows the identity relationship, as demonstrated by $37 \mathrm{~b}$, and cannot select an element from a salient set, as demonstrated by 39 c, they can refer back to an already selected salient element of a salient set as in $40 \mathrm{c}$.

\subsection{Summary of constraints on English preposing}

We have demonstrated that English preposing is salient given with functionally bipolar distribution and consonance between the scalar salient relationships at the poles. Further, 1) VP preposing is exceptional in being constrained to affirm or deny a presupposition, 2) identity relating preposed constituents are ruled out, and 3) the general condition of salient preposed constituent and salient OP makes preposed adjectives, adverbs of manner and pronouns infelicitous.

\section{Preposing in v-f Kashmiri}

If we now check for comparable constraints on preposing in Kashmiri, we find that the minimal necessary requirement of shared knowledge given, rather than salient given, its fundamental difference from English preposing, identified in section 2, also accounts for all its other differences from English preposing.

In this section, I will first illustrate that Kashmiri preposing accommodates the less given, shared knowledge counterparts of salient relationships which constrain felicitous English preposing. I will then demonstrate how this weaker condition of shared knowledge givenness effects the other defining features, identified above for English preposing: 1) bipolar distribution of functional content and consonance between the functions at the poles, 2) the affrimation/negation only condition on felicitous VP preposing, 3) the nonidentity constraint, and 4) the infelicity of preposed adjectives, adverbs of manner and pronouns.

\subsection{Shared knowledge preposing}

In our analysis of English preposing, we identified three possible scalar salient relationships that OPs can make to the proposition of the preceding clause: attribute of, in 16 , alternative to, in 18 , and prerequisite to, in 17 . In Kashmiri, the minimal 
condition of shared knowledge OP makes it possible to express the above-mentioned relationships either saliently or in shared knowledge version. Examples of preposings bearing the shared knowledge relationships of attribution, alternation and prerequisite to are given in 41,42 , and 43 , respectively.

41. Shared knowledge attribution:

totaa'n ees thiik so

until-then was all right she

$=$ Until then she was all right.

kath $(P C)^{6}$ ees karan

talk was doing

$=$ She was talking.

baath $(P C)$ ees karaan

$=$ She was talking.

cai eesin ceemits

tea had drunk

$=$ She had had her tea.

$\operatorname{dod}(P C)$ oosun coomut

milk had drunk

$=$ She had had her milk.

42. Shared knowledge alternation

tem pati chi palav

that after are clothes

$=$ Then come the clothes.

n'av palav chi suvnaavaan

new clothes are getting-made

$=$ They get new clothes made

preen palav $(P C) \quad$ 'chini tsinaan

old clothes are-not wearing

$=$ They don't wear the old clothes.

43. Shared knowledge prerequisite act:

tse anthi na'v palav khaandari kheetri

you did-you-buy new clothes wedding for

$=$ Did you buy new clothes for the wedding?

anha, magar pee $(n)$ si $(P C)$ gatsnam aasin

would-buy them, but money must have

= I would buy them, but I don't have the money.

agar nookri miijim tootaa'n

if job will-get by-then

$=$ If I have got a job by then,

teli ani

${ }^{6}$ The preposed constituent. 
then will-get

$=$ then I will get them.

The shared knowledge status of these preposings is evident in the fact that their OPs can be felicitously stated and denied in the context of the discourse to which they are bonded. This is illustrated in 44 , using the example of 41 :

44. Up until then she was fine.

Statement of shared knowledge: She was doing the things that people do when they are well.

Denial of shared knowledge: But she wasn't doing the things people generally do when they are well.

It is not possible to state or deny salient OPs. The statement of the presupposed OP, obtained by substituting a variable for the focal constituent of the preposing of $45 \mathrm{~b}$, in the context of $45 \mathrm{a}$ is redundant and the denial is so contrary to expectation that it describes extremely odd behaviour:

; a. They had a baby.

b. 'Tom they called him.

Statement of preposupposition: They gave him a name.

Denial of presupposition: But they did not give him a name.

The difference between the two ways to the relationships of attribution, alternation, and prerequisite to is the fundamental difference between shared knowledge and salient given, that salient given is an instance of what is already assumed to be in association with the proposition to which it is salient, while shared knowledge is an instance of what is merely common knowledge as possible. So, shared knowledge attribution is only recognized as possible, while its salient manifestation is an instance of an inherent attribute: in 41, chatting away when one is well is probable or likely but not inevitable, whereas the attributive act of naming is inevitable in contexts such as $45 \mathrm{a}$, where naming is inevitably connected to the event of having the baby.

We can demonstrate the greater distance between shared knowledge relationship of proposition and its attributive/alternative/prerequisite, as compared to the salient relationship between these, by juxtaposing the two environments in which a single clause instances the shared knowledge and salient versions of attrbution/alternation/ prerequisite to.

Shared knowledge attribution, which is not felicitous in preposed version in English, demonstrated in 46, can be made salient by altering the preceding discourse, 47:

46. Until then she was all right.

\# 'Tea she had had./ She had had tea.

47. She did not want tea.

But tea she had had. 
Juxtaposing the two attributive relationships of 46 and 47 gives us 1) being all right to having had tea, and 2) not wanting tea to having had tea, and clearly demonstrates the greater distance of shared knowledge attribution from preceding proposition, as compared to the relationship between salient attribution and its preceding proposition.

Infelicitous too in preposed version in English is shared knowledge alterantion, demonstrated in 48. To make this alternation salient and therefore felicitous in preposed form, the preceding context is modified as in, for example, 49:

48. After that come the clothes.

They get new clothes made,

\# The old clothes they 'don't wear./They 'don't wear the old clothes.

49. After that come the clothes.

Everyone buys new clothes.

The old ones they simply 'throw away.

Again, a simple juxtaposition of 1) not wearing old clothes to buying new ones, and 2) throwing away old clothes to buying new ones is suggestive of the greater dista: $\cdots$ between the shared knowledge relationship of proposition and its alternative, compared to the salient relationship between these.

Like the attributive and alternative relationships, the shared knowledge relationship of prerequisite to is infelicitous in English preposing, demonstrated in 50. To make it a felicitous preposing, the preceding context must be modified as in, for example, 51:

50. Will you buy new clothes for the wedding?

\# I would, but the money I 'don't have.

51. For vacations you must have time and money.

Money I don't have.

Again, simply juxtaposing the two versions of the relationships of prerequisite to is suggestive of the greater distance of the shared knowledge relationship and preceding proposition compared to the salient relationship and preceding proposition: 1) having money to buying new clothes, and 2) needing money to having money.

The above examples were constructed so that the same clause would relate back with a single relationship, but with two levels of givenness, repeated below:

Attribution: shared knowledge: having had tea to the state of being well salient: having had tea to not wanting it

Alternation: shared knowledge: not wearing old clothes to buying new ones salient: throwing away old clothes to buying new ones

Prerequisite: shared knowledge: having money to buying new clothes salient: having money to needing money

This demonstrates that when the speaker chooses to relate to the proposition of the preceding clause through relationships such as attribution, alternation or prerequisite to, he can do so in Kashmiri preposing either by instantiating what is considered merely 
possible or probable about the proposition in question, or by instantiating a domain inherent to or presupposed by the proposition. In English Topicalization and Focus-Movement, on the other hand, he is constrained to make given relationships to the preceding proposition by instantiating inherent domains.

\subsection{Givenness and bipolarity}

Checking for presence of the feature of functional bipolarity, a concomitant of salience in English preposing, we find that felicitous Kashmiri preposing falls into two broad categories: When preposing in Kashmiri is salient it behaves exactly like English preposing. Like English preposing, it comprises a salient preposed constituent and a consonant salient $\mathrm{OP}$, as in 52 :

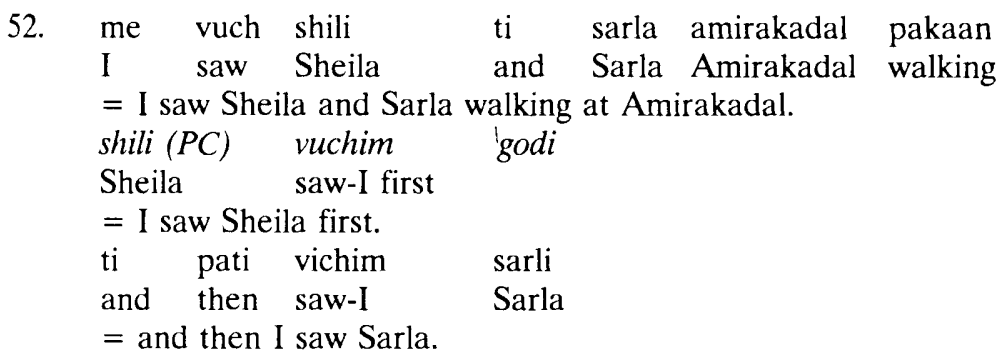

This salient subset is not, however, what identifies preposing in Kashmiri. The identifying, more encompassing, set of shared knowledge preposing is not constrained to be bipolarly distributed; and it is not therefore always possible to identify the separate scalar relationships of preposed constituent and OP, demonstrated in 53:

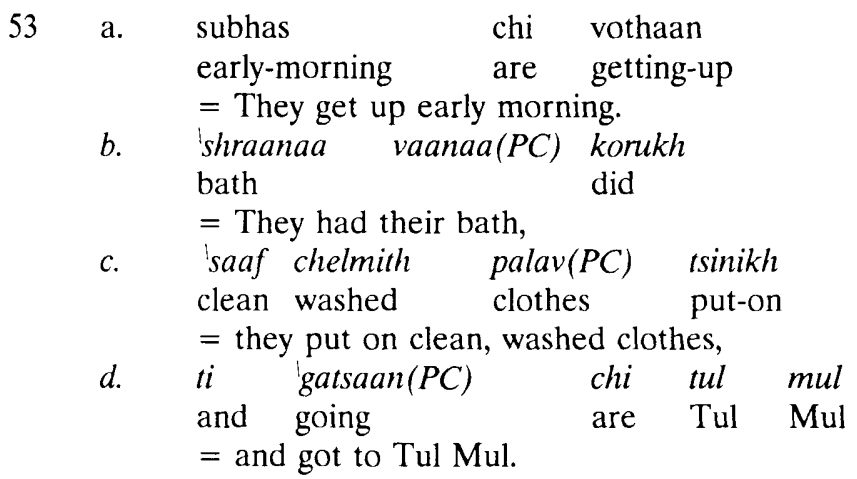

This implies that the greater givenness of English preposing is a consequence of the consonance constraints on the givenness of preposed constituent and OP, i.e., English preposing is more given because not only is the proposition as a whole given relative 
to its preceding discourse, but in addition the given relation of the OP must accommodate the given relation of the preposed constituent.

\subsection{Kashmiri main verb preposing}

Main verb preposing in Kashmiri is minimally constrained to affirm or deny shared knowledge to the preceding discourse: it selects the option of affirmation or negation from the variable of affirmation/negation of the shared knowledge OP, illustrated in $53 \mathrm{~d}$ and 54 .

54. me ees naa dari saaf karin?

I had not windows clean to-do?

$=$ Do you remember that I had those windows to clean?

Shared knowledge OP: Ix (x: did/did not) clean them.

subhey vothus

early-morning got-up-I

$=$ I got up early in the morning,

ti karem $(P C)$ saaf

and did-them clean

$=$ and cleaned them.

55. me ees naa dari saaf karin?

I had not windows clean to-do?

$=$ Do you remember that I had those windows to clean?

tim karem ni

those did not

$=$ I didn't do them.

Shared knowledge OP: I did y (y:something else that needed doing).

magar bakai seeri keem 'mokleemvim

but rest all work finished-I

$=$ But I finished everything else.

\# magar 'mokleevim(PC) bakai keem seeri

but finished-I else work all

$=$ But $\mathrm{I}$ finished everything else.

55 demonstrates that the general constraint of shared knowledge OP is by itself insufficient to allow for felicitous VP preposing.

Compared to its English counterpart, Kashmiri VP preposing, therefore, differs only in that it is minimally shared knowledge rather than salient given, since English preposing, as illustrated in section 2.2.1, is constrained to affirm or deny a presupposition. 


\subsection{The nonidentity correlate}

In Kashmiri, as in English (cf. section 2.2.2), the preposing of 56b is infelicitous, even though it instantiates a salient OP.

$\begin{array}{cllll}56 & \text { a. } & \text { tse } & \text { parthi } & \text { m'een disateshn? } \\ & \text { you } & \text { read } & \text { my dissertation? } \\ & =\text { Did you read my dissertation? } & \\ \text { b. } & ? & \text { so }(P C) & \text { parim } \\ & & \text { it } & \text { read-I } & \\ \text { c. } & ? & \text { 'ceen disateshn(PC) } & \text { parim } \\ & & \text { your dissertation } & \text { read-I } \\ & & \text { parim } & \\ & \text { read-it-I }\end{array}$

It is only felicitous if the listener perceives 'the dissertation' as an element of a salient set, rather than as bearing the relationship of identity. The nonidentity constraint, however, does not apply to shared knowledge Kashmiri preposing. The shared knowledge OP is not constrained by the requirement that the preposed constituent instantiate a variable (cf. section 2.2.2 for evidence of this constraint on salient $O P$ ), and therefore the preposing of $57 \mathrm{~b}$ is felicitous:

57 a.

asi a'n na'v palav

we bought new clothes

$=$ We bought some new clothes.

shared knowledge: asi kor k'aataamath timan

b. $\begin{array}{lll}\text { we did something to-them } \\ \text { ti } \operatorname{tim}(P C) \text { dit asi vjesan }\end{array}$

and them gave we girl friends-to

$=\quad$ and we gave them to our girl friends.

The nonidentity constraint explains the infelicty of preposed pronouns both in English (cf. section 2.2.3.) and salient Kashmiri preposing (example 56b). But since identity is felicitous in Kashmiri shared knoweldge OPs, so too is pronominal preposing (57b). Pronominal preposing in Kashmiri is therefore limited to shared knowledge propositions.

\subsection{Preposing adjectives, adverbs of manner and pronouns}

The weaker condition of shared knowledge rather than salience on Kashmiri preposing also makes it possible to prepose adjectives, adverbs of manner and pronouns.

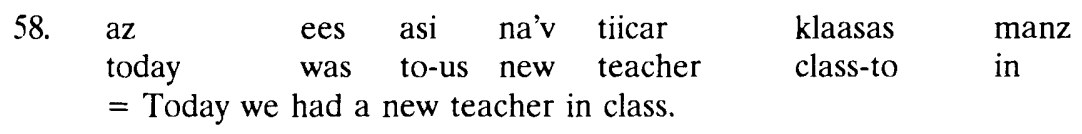




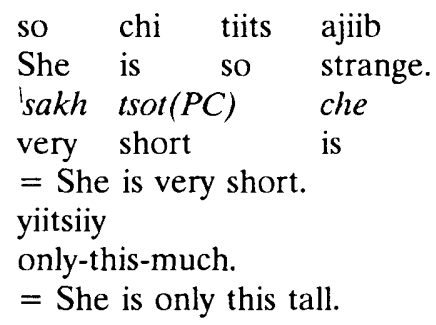

The adjectival preposing of 58 relates back with a shared knowledge relationship to the proposition of the preceding clause: It is an instance of the shared knowledge OP that the teacher is strange is some way. Likewise, because Kashmiri preposing is not constrained to relate back saliently, the shared knowledge and therefore infelicitous English preposing of 33 is felicitous in Kashmiri, as is demonstrated by 59B:

59. A: so mahara chi khubsurath ti calaakh
she, sir, is beautiful and clever
$=$ She is both beautiful and clever.
B: na sa, khubsurath(PC) che ni

It is an instance of the shared knowledge that she does not have both the attributes of intelligence and beauty.

Similarly, adverbs of manner, which are also found in shared knowledge propositions, are felicitously preposed. Hence, the infelicitous adverbial English preposing of 35, is felicitous in Kashmiri, demonstrated in 60B.

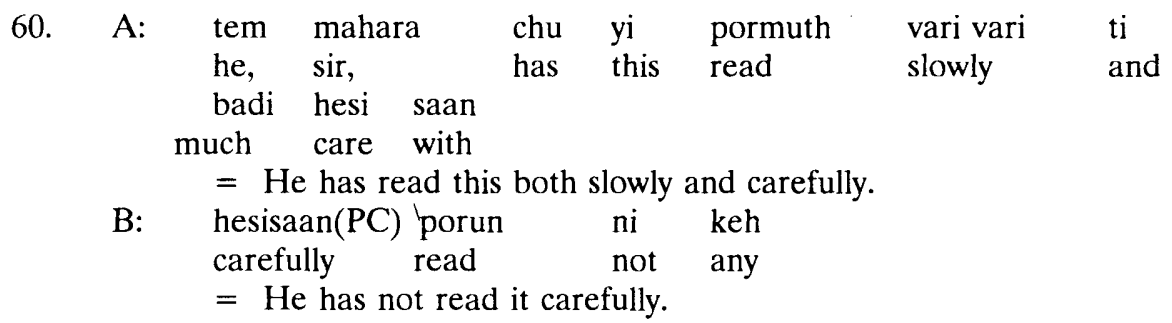

It is an instance of the shared knowledge that it is possible the reading was not done both slowly and carefully. While this is not presupposed at the time of the utterance of $\mathrm{B}$, it is shared knowledge to it and in being so meets the minimal condition of Kashmiri preposing.

As regards pronominal preposing, we have shown in section 3.4 that pronouns are preposable in Kashmiri only when the OP is shared knowledge, 61; a salient $\mathrm{OP}$ does not allow preposing.

$\begin{array}{llll}\text { 61. asi a'n } & \text { na'v palav } \\ \text { we } & \text { bought } & \text { new clothes }\end{array}$


$=$ We bought some new clothes.

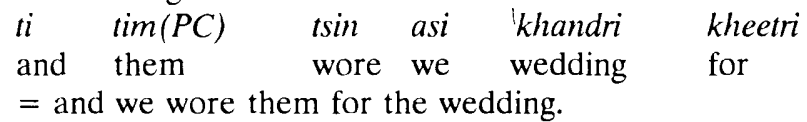

\section{Conclusion}

The comparative analysis of this study has demonstrated that preposing in Kashmiri is functionally distinct from English Topicalization and Focus-Movement in the following ways:

1. The preposed constituent and OP are allowed to be shared knowledge versions of such scalar relationships as attribution, prerequisite to, or alternative to, rather than the salient counterparts of these relationships.

2. Functional bipolarity and consonance between the relationships at the poles is found for salient propositions, but is not a condition on felicitous preposing.

3. Main verb preposing in Kashmiri must affirm or deny the shared knowledge given relationship. Therefore, the minimal requirement of shared knowledge, rather than salient given, is the only difference between Kashmiri and English main verb preposing. 4. Unlike English, the preposed constituent can relate back with identity, but can only do so when the proposition is shared knowledge; salient propositions cannot relate back with identity. In consequence, pronouns are preposable only in shared knowledge nonsalient propositions.

5. And finally, adjectives and adverbs of manner are preposable because they do not violate the minimal condition on felicitous Kashmiri preposing by having shared knowledge propositions.

We have identified weaker functional constraint on Kashmiri as compared to English preposing and therefore a heretofore unrecorded type of word order flexibility. The question that this inevitably poses and that subsequent studies must tackle is whether such flexibility is a systemic feature of this and other v-f languages, making v-f constructions in general less functionally constrained than their $v-m$ counterparts and implying that the grammar of $v$-f codes less subtle pragamtic distinctions than $v-m$.

\section{References}

Bland, S. (1980) "Topic/comment sentences in English". (ms.)

Creider, C. (1979) "On the explanation of transformations". In Givon (ed.), Syntax and Semantics 12: Discourse and Syntax. New York: Academic Press, 3-22.

Davison, A. (1984) "Syntactic markedness and the definition of sentence topic". Language 60:4.797-846.

Givon, Talmy (1984) Syntax: A functional-typological introduction. Vol.1. Amsterdam: J. Benjamins. 
Gundel, J. (1974) "The role of topic and comment in linguistic theory". University of Texas dissertation.

Halliday, M.A.K. (1967) "Notes on transitivity and theme in English". Journal of Linguistics Part 2.

Langacker, A. (1974) "Movement rules in functional perspective". Language 50:4.630-64.

Prince, E. F. (1981a) "Toward a taxonomy of given-new information". In P. Cole (ed.), Radical Pragmatics. New York: Academic Press, 223-255.

Prince, E.F. (1981b) "Topicalization, focus-movement, and Yiddish-movement: A pragmatic differentiation". Proceedings of the Seventh Annual Meeting, Berkeley Linguistics Society, ed. by Alford, D. et al, 249-64.

Prince, E.F. (1984) "Topicalization and left-dislocation: A functional analysis. Discourses in reading and linguistics". In S.J. White and V. Teller (eds.), Annals of the New York Academy of Sciences V, 213-25.

Reinhart, T. (1981) "Pragmatics and linguistics: An analysis of sentence topics". Philosophica 27-53-94. Rodman, R. (1974) "On left dislocation". Papers in Linguistcs 7.437-66.

Tickoo, A. (1990). "On preposing and word order rigidity". A University of Pennsylvania dissertation. Ward, G. (1985) "The semantics and pragmatics of preposing". A University of Pennsylvania dissertation. Ward, G. (1990). "The discourse functions of VP preposing". Language. 66:4.742-63

ASHA TICKOO. 600 West Harvey Street \#A 920, Philadelphia, PA 19144, United States of America. 